\title{
Modeling and Forecasting Mortality Using the Lee-Carter Model for Indian Population Based on Decade-wise Data
}

\author{
Rajendra N. Chavhan and Ramkrishna L. Shinde* \\ Department of Statistics and Actuarial Science, School of Mathematical \\ Sciences, North Maharashtra University, Jalgaon Jalgaon-425001, Maharashtra, \\ India \\ *Corresponding Author: rlshinde@nmu.ac.in
}

Received: $25^{\text {th }}$ February 2015 / Revised: $29^{\text {th }}$ February 2016 / Accepted: $14^{\text {th }}$ March 2016 CIAppStat-SL2016

\begin{abstract}
The stochastic mortality model given by Lee and Carter (1992) has been used in literature for fitting and forecasting the human mortality. We have modeled mortality rates of Indian population using the Lee-Carter $(L C)$ model based on decade-wise data available separately for Indian female and male populations in the form of life tables for the period 1901-2011. The Singular Value Decomposition (SVD) approach is used for estimation of the parameters of the LC model. Forecasted values of time dependent parameter $k_{t}$ of the LC model are obtained for next five decades using best fitted auto regressive integrated moving average (ARIMA) model. Forecasted values of life expectancy at different ages with $95 \%$ confidence intervals are also reported for the next five decades. As an application, using forecasted mortality rates for the next five decades, net single premium for whole life and term insurance, actuarial present values of life annuities for some selected ages are also evaluated.
\end{abstract}

Keywords: Lee-Carter (LC) model, Mortality modeling, Forecasting, Life expectancy, Singular value decomposition (SVD), Net single premium (NSP).

\section{Introduction}

Mortality modeling and its forecasting have been a major research area for the practitioners in actuarial science and demography. During the last century many countries have experienced considerable improvements in mortality rates. Dramatic decline in mortality brings very serious financial exposures for insurers 
providing life contracts, life annuities. Population forecasts are used for policy making and pricing insurance products.

Lee and Carter (1992) introduced the first mortality model with stochastic forecast. In this model time dependent factor $k_{t}$ is modeled through time series models. Singular Value Decomposition (SVD) was used by Lee and Carter (1992) for the parameter estimation. Due to its simplicity in the parameter estimation, Lee-Carter (LC) model became more popular. The LC model has been used for fitting and forecasting the mortality rates for many countries: US (Lee and carter, 1992), Chile (Lee and Rofman, 1994), China (Lin,1995), Japan (Wilmoth, 1996), the seven most economically developed nations (G7) (Tuljapurkar et al., 2000), India (Singh and Ram,2004 and Yadav et. al. 2012), the Nordic countries (Kossi et. al., 2006), Sri Lanka (Aberathna et. al., 2014) and Thai (Yasungnoen and Sattayatham, 2016). Singh and Ram (2004) modeled Indian mortality by LC model and forecasted life expectancy at birth using Sample Registration System (SRS) data for the years 1970 to 2002. Yadav et.al (2012) also used LC model and forecasted age specific death rates up to year 2025 for Indian female and male population based on SRS data for the years 1981 to 2006. In the present work, we have used the decade-wise life table data (from 1901-11 to 2001-11) and modeled the Indian mortality by LC model using SVD. We have forecasted the future mortality rates for both female and male populations for the period decades 1911-21 to 1951-61. Forecasted values of life expectancy at different ages with $95 \%$ confidence interval are obtained and reported for next five decades. Actuarial quantities evaluated based on forecasted mortality are also reported.

The rest of the paper is organized as follows: In Section 2, we discuss the data used in this paper. In Section 3, we have presented some results about changes in mortality pattern in India during last century. The LC model and modeling procedure is discussed in Section 4. Section 5 gives the results of fitted model. Section 6 deals with results on the mortality forecasting for India. In Section 7 , as an application of study, we have presented some actuarial calculation. Conclusions are reported in Section 8.

\section{Data Description}

Our study is based on data obtained from abridged life tables of Indian population for 11 decades from 1901-1911 to 2001-2011. These life tables are taken from the websites www.lifetable.de and www.who.org.in. Life tables of Indian female and male populations are separately available for the decades 1901-1911 to 1971-1981 for the ages 0, 1-4 and 5-80 (quinquennial) and 80+ whereas for the decades 1981-1991 to 2001-2011 these life tables are available for the ages $0,1-4$ and 5-100 (quinquennial) and 100+. To maintain uniformity in our data, we have converted the life tables of the decades 1981-91 to 2001-11 
for the ages $0,1-4$ and 5-80 (quinquennial) and 80+. From these life tables, we have derived decade-wise age group specific central death rates $\left(m_{x, t}\right)$ as

$$
m_{x, t}=\frac{D_{x, t}}{L_{x, t}}
$$

where,

$D_{x, t}$ denotes the number of deaths in the age group $x$ during decade $t$.

$L_{x, t}$ denotes the average number of persons in the age group $x$ during decade $t$.

$m_{x, t}$ is also known as central rate of mortality or central mortality rate for age group $x$ during decade $t$. Data on decade-wise age group specific central death rates for Indian female and male populations are reported in Table 1 and Table 2 respectively.

Table 1: Decade-wise age group specific central death rates for Indian female population during 1901-1911 to 2001-2011

\begin{tabular}{|c|c|c|c|c|c|c|c|c|c|c|c|}
\hline $\begin{array}{c}\text { Age } \\
\text { Grou } \\
\mathbf{p}\end{array}$ & $\begin{array}{c}\mathbf{1 9 0 1 -} \\
\mathbf{1 1}\end{array}$ & $\begin{array}{c}\mathbf{1 9 1 1 -} \\
\mathbf{2 1}\end{array}$ & $\begin{array}{c}\mathbf{1 9 2 1 -} \\
\mathbf{3 1}\end{array}$ & $\begin{array}{c}\mathbf{1 9 3 1 -} \\
\mathbf{4 1}\end{array}$ & $\begin{array}{c}\mathbf{1 9 4 1 -} \\
\mathbf{5 1}\end{array}$ & $\begin{array}{c}\mathbf{1 9 5 1 -} \\
\mathbf{6 1}\end{array}$ & $\begin{array}{c}\mathbf{1 9 6 1 -} \\
\mathbf{7 1}\end{array}$ & $\begin{array}{c}\mathbf{1 9 7 1 -} \\
\mathbf{8 1}\end{array}$ & $\begin{array}{c}\mathbf{1 9 8 1 -} \\
\mathbf{9 1}\end{array}$ & $\begin{array}{c}\mathbf{1 9 9 1 -} \\
\mathbf{0 1}\end{array}$ & $\begin{array}{c}\mathbf{2 0 0 1 -} \\
\mathbf{1 1}\end{array}$ \\
\hline 0 & 0.3731 & 0.3789 & 0.2991 & 0.2549 & 0.2154 & 0.1664 & 0.1556 & 0.1449 & 0.0899 & 0.0703 & 0.0510 \\
\hline $1-4$ & 0.0574 & 0.0583 & 0.0463 & 0.0394 & 0.0331 & 0.0250 & 0.0232 & 0.0213 & 0.0096 & 0.0066 & 0.0039 \\
\hline $5-9$ & 0.0143 & 0.0139 & 0.0129 & 0.0114 & 0.0098 & 0.0078 & 0.0060 & 0.0044 & 0.0034 & 0.0023 & 0.0012 \\
\hline $10-14$ & 0.0114 & 0.0111 & 0.0103 & 0.0091 & 0.0078 & 0.0062 & 0.0048 & 0.0035 & 0.0017 & 0.0014 & 0.0009 \\
\hline $15-19$ & 0.0176 & 0.0171 & 0.0159 & 0.0141 & 0.0120 & 0.0096 & 0.0073 & 0.0054 & 0.0029 & 0.0024 & 0.0014 \\
\hline $20-24$ & 0.0227 & 0.0220 & 0.0204 & 0.0181 & 0.0155 & 0.0123 & 0.0095 & 0.0069 & 0.0037 & 0.0031 & 0.0019 \\
\hline $25-29$ & 0.0233 & 0.0227 & 0.0210 & 0.0186 & 0.0160 & 0.0127 & 0.0097 & 0.0071 & 0.0034 & 0.0032 & 0.0018 \\
\hline $30-34$ & 0.0243 & 0.0236 & 0.0219 & 0.0194 & 0.0166 & 0.0132 & 0.0101 & 0.0074 & 0.0033 & 0.0031 & 0.0020 \\
\hline $35-39$ & 0.0268 & 0.0260 & 0.0241 & 0.0214 & 0.0184 & 0.0146 & 0.0112 & 0.0082 & 0.0039 & 0.0033 & 0.0025 \\
\hline $40-44$ & 0.0308 & 0.0299 & 0.0277 & 0.0246 & 0.0211 & 0.0168 & 0.0129 & 0.0094 & 0.0048 & 0.0041 & 0.0031 \\
\hline $45-49$ & 0.0372 & 0.0361 & 0.0335 & 0.0297 & 0.0255 & 0.0203 & 0.0157 & 0.0115 & 0.0068 & 0.0058 & 0.0042 \\
\hline $50-54$ & 0.0463 & 0.0449 & 0.0418 & 0.0371 & 0.0319 & 0.0255 & 0.0197 & 0.0144 & 0.0104 & 0.0092 & 0.0065 \\
\hline $55-59$ & 0.0594 & 0.0576 & 0.0536 & 0.0478 & 0.0412 & 0.0342 & 0.0256 & 0.0188 & 0.0162 & 0.0152 & 0.0109 \\
\hline $60-64$ & 0.0776 & 0.0753 & 0.0702 & 0.0628 & 0.0544 & 0.0439 & 0.0342 & 0.0253 & 0.0269 & 0.0220 & 0.0201 \\
\hline $65-69$ & 0.1056 & 0.0995 & 0.0931 & 0.0838 & 0.0731 & 0.0596 & 0.0467 & 0.0348 & 0.0436 & 0.0381 & 0.0312 \\
\hline $70-74$ & 0.1296 & 0.1318 & 0.1240 & 0.1125 & 0.0992 & 0.0819 & 0.0651 & 0.0490 & 0.0649 & 0.0556 & 0.0540 \\
\hline $75-79$ & 0.1776 & 0.1734 & 0.1644 & 0.1511 & 0.1352 & 0.1138 & 0.0921 & 0.0707 & 0.0843 & 0.0823 & 0.0746 \\
\hline $80+$ & 0.3145 & 0.3120 & 0.3074 & 0.3004 & 0.2916 & 0.2793 & 0.2660 & 0.2522 & 0.1578 & 0.1302 & 0.1429 \\
\hline
\end{tabular}

\section{Mortality Pattern in India}

To demonstrate the improvement in Indian mortality in Figure 1, we have plotted age group specific central death rates for Indian female and male 
Table 2: Decade-wise age group specific central death rates for Indian male population during 1901-1911 to 2001-2011

\begin{tabular}{|c|c|c|c|c|c|c|c|c|c|c|c|}
\hline $\begin{array}{c}\text { Age } \\
\text { Grou } \\
\mathbf{p}\end{array}$ & $\begin{array}{c}\mathbf{1 9 0 1 -} \\
\mathbf{1 1}\end{array}$ & $\begin{array}{c}\mathbf{1 9 1 1}- \\
\mathbf{2 1}\end{array}$ & $\begin{array}{c}\mathbf{1 9 2 1 -} \\
\mathbf{3 1}\end{array}$ & $\begin{array}{c}\mathbf{1 9 3 1 -} \\
\mathbf{4 1}\end{array}$ & $\begin{array}{c}\mathbf{1 9 4 1 -} \\
\mathbf{5 1}\end{array}$ & $\begin{array}{c}\mathbf{1 9 5 1 -} \\
\mathbf{6 1}\end{array}$ & $\begin{array}{c}\mathbf{1 9 6 1 -} \\
\mathbf{7 1}\end{array}$ & $\begin{array}{c}\mathbf{1 9 7 1 -} \\
\mathbf{8 1}\end{array}$ & $\begin{array}{c}\mathbf{1 9 8 1}- \\
\mathbf{9 1}\end{array}$ & $\begin{array}{c}\mathbf{1 9 9 1 -} \\
\mathbf{0 1}\end{array}$ & $\begin{array}{c}\mathbf{2 0 0 1 -} \\
\mathbf{1 1}\end{array}$ \\
\hline 0 & 0.35864 & 0.36419 & 0.28804 & 0.24569 & 0.20785 & 0.16071 & 0.15031 & 0.14005 & 0.08210 & 0.06432 & 0.04672 \\
\hline $1-4$ & 0.04623 & 0.04692 & 0.03719 & 0.03152 & 0.02635 & 0.01925 & 0.01755 & 0.01593 & 0.00881 & 0.00609 & 0.00357 \\
\hline $5-9$ & 0.01355 & 0.01330 & 0.01227 & 0.01065 & 0.00869 & 0.00665 & 0.00478 & 0.00323 & 0.00280 & 0.00187 & 0.00126 \\
\hline $10-14$ & 0.01065 & 0.01043 & 0.00961 & 0.00832 & 0.00677 & 0.00517 & 0.00371 & 0.00250 & 0.00165 & 0.00141 & 0.00087 \\
\hline $15-19$ & 0.01687 & 0.01656 & 0.01531 & 0.01332 & 0.01089 & 0.00837 & 0.00603 & 0.00408 & 0.00199 & 0.00184 & 0.00145 \\
\hline $20-24$ & 0.02208 & 0.02172 & 0.02013 & 0.01757 & 0.01442 & 0.01111 & 0.00804 & 0.00545 & 0.00276 & 0.00253 & 0.00213 \\
\hline $25-29$ & 0.02275 & 0.02239 & 0.02076 & 0.01812 & 0.01487 & 0.01147 & 0.00830 & 0.00563 & 0.00307 & 0.00322 & 0.00241 \\
\hline $30-34$ & 0.02371 & 0.02335 & 0.02166 & 0.01892 & 0.01554 & 0.01199 & 0.00868 & 0.00589 & 0.00364 & 0.00385 & 0.00328 \\
\hline $35-39$ & 0.02634 & 0.02594 & 0.02409 & 0.02107 & 0.01733 & 0.01340 & 0.00972 & 0.00661 & 0.00462 & 0.00511 & 0.00448 \\
\hline $40-44$ & 0.03051 & 0.03008 & 0.02797 & 0.02452 & 0.02022 & 0.01567 & 0.01140 & 0.00777 & 0.00637 & 0.00644 & 0.00578 \\
\hline $45-49$ & 0.03725 & 0.03678 & 0.03428 & 0.03015 & 0.02495 & 0.01941 & 0.01417 & 0.00969 & 0.01038 & 0.00932 & 0.00820 \\
\hline $50-54$ & 0.04700 & 0.04648 & 0.04346 & 0.03839 & 0.03194 & 0.02499 & 0.01834 & 0.01260 & 0.01522 & 0.01374 & 0.01234 \\
\hline $55-59$ & 0.06106 & 0.06050 & 0.05663 & 0.05046 & 0.04230 & 0.03334 & 0.02465 & 0.01706 & 0.02380 & 0.02190 & 0.01669 \\
\hline $60-64$ & 0.08086 & 0.08027 & 0.07575 & 0.06781 & 0.05739 & 0.04573 & 0.03416 & 0.02387 & 0.03627 & 0.03061 & 0.02850 \\
\hline $65-69$ & 0.10798 & 0.10744 & 0.10205 & 0.09227 & 0.07912 & 0.06399 & 0.04853 & 0.03438 & 0.05407 & 0.04950 & 0.04240 \\
\hline $70-74$ & 0.14400 & 0.14352 & 0.13738 & 0.12589 & 0.10985 & 0.09063 & 0.07023 & 0.05076 & 0.07709 & 0.06631 & 0.06750 \\
\hline $75-79$ & 0.18961 & 0.18946 & 0.18296 & 0.17031 & 0.15195 & 0.12891 & 0.10293 & 0.07666 & 0.10305 & 0.09781 & 0.09022 \\
\hline $80+$ & 0.32154 & 0.32155 & 0.31860 & 0.31263 & 0.30334 & 0.29080 & 0.27562 & 0.25890 & 0.16049 & 0.13974 & 0.15024 \\
\hline
\end{tabular}

populations. Overall there has been decline in mortality rates in India during 1901 to 2011 for both female and male populations. We have observed higher level of decline in mortality rates during 1961 to 2011 as compared to 1901 to 1961. Also rapid decline is observed in central mortality rates of Indian female population than male population from 1951-61 to 2001-11 for the ages 35-74 years.

Using data on life tables we have obtained life expectancies (LE) for female and male populations for all decades. Results obtained on LE are reported in Table 3 for some selected age groups. In India, Life expectancy at birth has been increased from 23.23 years to 67.30 years for female and from 24.76 years to 63.81 years for male during last century. During decades 1901-11, 1911-21 and 1921-31, life expectancy of Indian female and male at age group 20-24 was higher than life expectancy at birth. This is due to high rate of infant mortality during these decades. 
Modeling and Forecasting Mortality Using the Lee-Carter Model for Indian Population

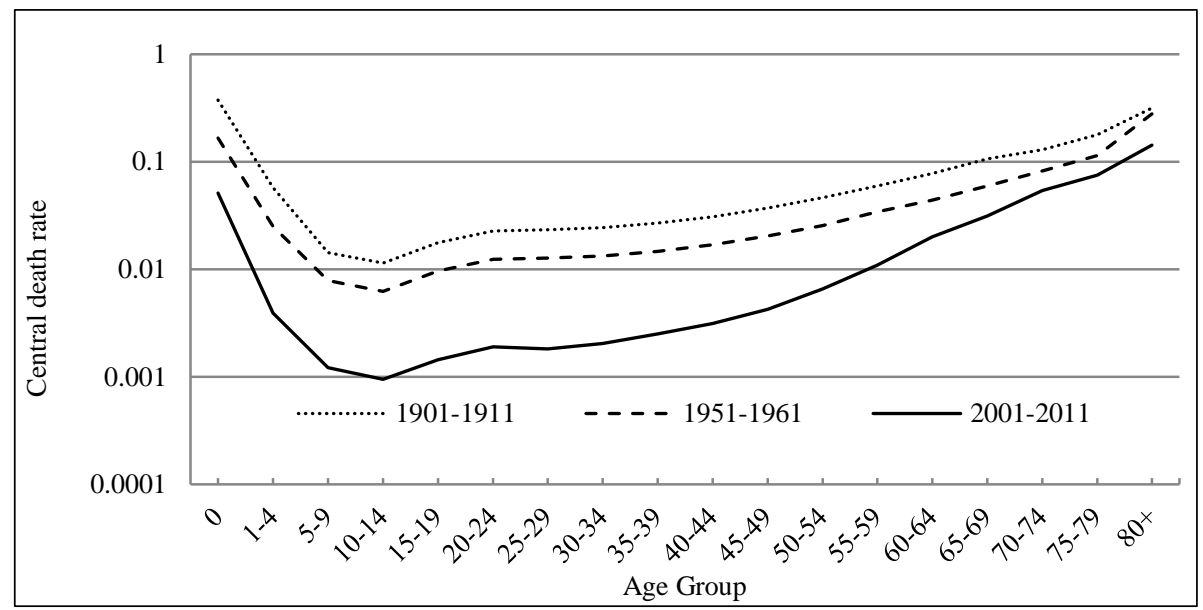

(a) Female Population

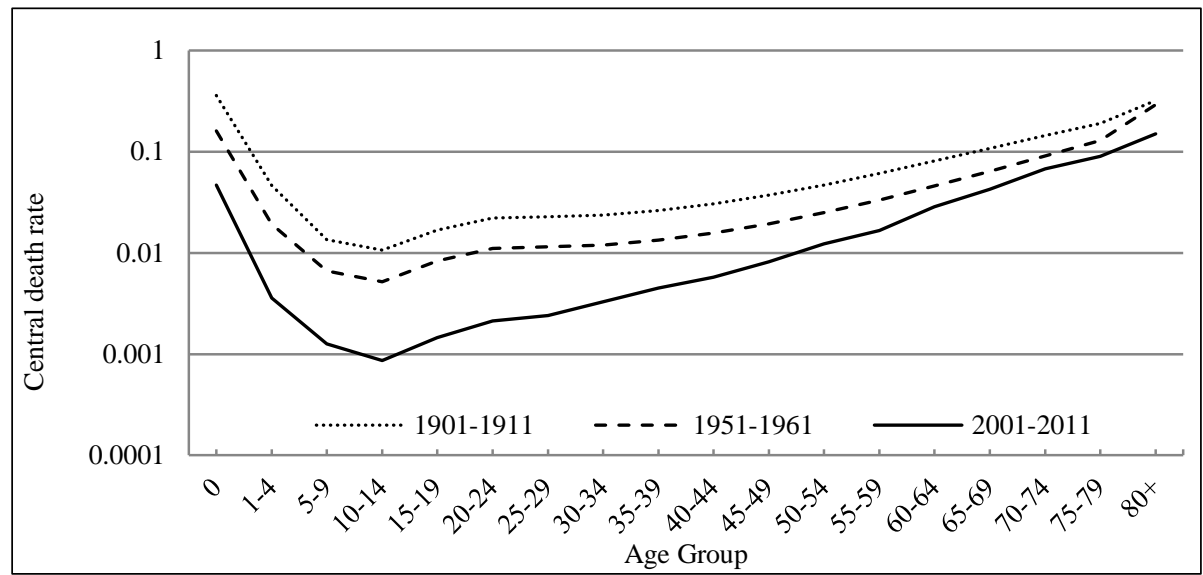

(b) Male Population

Figure 1: Pattern of age group specific central death rates for Indian Population

\section{Lee-Carter Model and Parameter Estimation}

\subsection{Lee-Carter Model}

Lee and Carter (1992) introduced the first stochastic mortality model for modeling human mortality as given by,

$$
\ln \left(m_{x, t}\right)=a_{x}+b_{x} k_{t}+\varepsilon_{x, t}
$$


Table 3: Life expectancy (in years) of Indians during 1901-2011 at selected age

\begin{tabular}{|c|c|c|c|c|c|c|c|c|}
\multicolumn{1}{|c}{ groups } \\
\hline \multirow{3}{*}{ Decade } & \multicolumn{9}{|c|}{ At Age Group } \\
\cline { 2 - 9 } & At Birth & \multicolumn{2}{|c|}{$20-24$} & \multicolumn{2}{c|}{$40-44$} & \multicolumn{2}{c|}{$60-64$} \\
\cline { 2 - 9 } & Female & Male & Female & Male & Female & Male & Female & Male \\
\hline $1901-11$ & 23.23 & 24.76 & 27.10 & 27.21 & 18.08 & 17.91 & 9.29 & 8.98 \\
\hline $1911-21$ & 23.34 & 24.74 & 27.55 & 27.42 & 18.39 & 18.02 & 9.47 & 9.02 \\
\hline $1921-31$ & 26.97 & 28.26 & 28.68 & 28.48 & 19.15 & 18.69 & 9.89 & 9.33 \\
\hline $1931-41$ & 30.25 & 31.63 & 30.51 & 30.42 & 20.38 & 19.93 & 10.56 & 9.96 \\
\hline $1941-51$ & 34.09 & 35.91 & 32.85 & 33.26 & 21.97 & 21.78 & 11.44 & 10.92 \\
\hline $1951-61$ & 39.89 & 42.04 & 36.24 & 36.96 & 24.23 & 24.27 & 12.77 & 12.27 \\
\hline $1961-71$ & 44.27 & 46.98 & 40.23 & 41.41 & 27.05 & 27.35 & 14.32 & 14.01 \\
\hline $1971-81$ & 49.13 & 52.45 & 44.59 & 46.34 & 30.14 & 30.86 & 16.11 & 16.06 \\
\hline $1981-91$ & 58.70 & 57.58 & 48.79 & 46.27 & 31.70 & 28.84 & 15.82 & 14.21 \\
\hline $1991-01$ & 62.59 & 60.46 & 50.60 & 47.32 & 33.29 & 30.07 & 17.21 & 15.33 \\
\hline $2001-11$ & 67.30 & 63.81 & 52.92 & 48.73 & 34.71 & 31.09 & 17.67 & 15.72 \\
\hline
\end{tabular}

where,

$x$ denotes age group under consideration (here in our data, $x=0,1-4,5-9, \ldots, 75-$ $79,80+)$,

$t$ denotes period (decade) of life table under consideration (here in our data, $t=1901-11,1911-21, \ldots, 2001-11)$,

$m_{x, t}$ is the central rate of mortality for age group $x$ at time $t$,

$a_{x}$ denotes the coefficient which describes average age specific pattern of mortality,

$k_{t}$ denotes the time trend for the general mortality, $b_{x}$ denotes the coefficient which measures sensitivity of $\ln \left(m_{x, t}\right)$ at age-grouping $x$ as the $k_{t}$ varies and $\varepsilon_{x, t}$ denotes the error associated with age-grouping $x$ and time $t$.

The parameterization in (2) is invariant to transformations like $\left(a_{x}, b_{x}, k_{t}\right) \rightarrow$ $\left(a_{x}+c b_{x}, \frac{b_{x}}{d}, d\left(k_{t}-c\right)\right)$ for some constant $c$ and $d(d \neq 0)$. Therefore for unique solution the following constraints used by Lee and Carter (1992),

$$
\sum_{x} b_{x}=1 \text { and } \sum_{t} k_{t}=0
$$

\subsection{Parameter Estimation by Singular Value Decomposition (SVD)}

Lee and Carter (1992) estimated the parameters of the LC model given in equation (1) by the SVD method. The estimated parameter vector $\hat{a}_{x}$ is determined as the average over time of the logarithm of the central death rates as 
Modeling and Forecasting Mortality Using the Lee-Carter Model for Indian Population

$$
\hat{a}_{x}=\frac{1}{11} \sum_{t} \ln \left(m_{x, t}\right) \text { for } x=0,1-4,5-9, \ldots 75-79,80+
$$

To obtain estimated parameters $\hat{b}_{x}$ and $\hat{k}_{t}$, we applied singular value decomposition on matrix $\mathrm{Z}$, where

$$
\mathrm{Z}=\ln \left(m_{x, t}\right)-\hat{a}_{x}
$$

that is

Z

$$
=\left[\begin{array}{cccc}
\ln \left(m_{0,1901-11}\right)-\hat{a}_{0} & \ln \left(m_{0,1911-21}\right)-\hat{a}_{0} & \cdots & \ln \left(m_{0,2001-11}\right)-\hat{a}_{0} \\
\ln \left(m_{1-4,1901-11}\right)-\hat{a}_{1-4} & \ln \left(m_{1-4,1911-21}\right)-\hat{a}_{1-4} & \cdots & \ln \left(m_{1-4,2001-11}\right)-\hat{a}_{1-4} \\
\vdots & \ddots & \ddots & \vdots \\
\vdots & \ddots & \ddots & \vdots \\
\ln \left(m_{75-79,1901-11}\right)-\hat{a}_{75-79} & \ln \left(m_{75-79,1911-21}\right)-\hat{a}_{75-79} & \cdots & \ln \left(m_{75-79,2001-11}\right)-\hat{a}_{75-79} \\
\ln \left(m_{80+, 1901-11}\right)-\hat{a}_{80+} & \ln \left(m_{80+, 1911-21}\right)-\hat{a}_{80+} & \cdots & \ln \left(m_{80+, 2001-11}\right)-\hat{a}_{80+}
\end{array}\right]
$$

Applying SVD to the matrix $Z$, we achieve the decomposition

$$
S V D(Z)=\lambda_{1} P_{x, 1} Q_{t, 1}+\lambda_{2} P_{x, 2} Q_{t, 2}+\cdots+\lambda_{k} P_{x, k} Q_{t, k},
$$

where $k=\operatorname{rank}(Z), \lambda_{i}(i=1,2, \ldots, k)$ are the singular values in increasing order with $P_{x, i}$ and $Q_{t, i}(i=1,2, \ldots, k)$ as the corresponding left and right singular vectors. The approximation to the first term of $\operatorname{SVD}(\mathrm{Z})$ gives the estimates $\hat{b}_{x}=P_{x, 1}$ and $\hat{k}_{t}=\lambda_{1} Q_{t, 1}$. The LC model is popular due to its simplicity for the parameter estimation by SVD. The proportion of variation explained by the LC model is $\lambda_{1}^{2} / \sum_{\mathrm{i}=1}^{\mathrm{k}} \lambda_{\mathrm{i}}^{2}$.

\section{Fitting of the LC Model to Indian Mortality Data}

This section presents the results of estimation of parameters in LC model. Estimated values of age dependent parameters $a_{x}$ and $b_{x}$ are reported in Table 4 and estimated values of time dependent parameter $k_{t}$ is reported in Table 5 for female and male populations in India based on decade-wise life tables (1901-11 to 2001-11). For SVD analysis, we have used MATLAB program.

From SVD analysis, we found that $98.16 \%$ and $96.47 \%$ variation explained by fitted LC model for Indian female and male mortality data respectively. In Figure 2, we have plotted observed and fitted age group specific central death rates for three decades, 1901-11, 1951-61 and 2001-11. We observed that the fitted mortality rates are very close to observed (actual) mortality rates except for lower and higher ages for the decade 2001-11. 
Table 4: $\hat{a}_{x}$ and $\hat{b}_{x}$ for Indian population based on decade-wise life tables (1901-11 to 2001-11)

\begin{tabular}{|c|c|c|c|c|}
\hline \multirow{2}{*}{$\begin{array}{c}\text { Age } \\
\text { Group }(\boldsymbol{x})\end{array}$} & \multicolumn{2}{|c|}{$\widehat{\boldsymbol{a}}_{\boldsymbol{x}}$} & \multicolumn{2}{c|}{$\widehat{\boldsymbol{b}}_{\boldsymbol{x}}$} \\
\cline { 2 - 5 } & Female & Male & Female & Male \\
\hline 0 & -1.7897 & -1.8410 & 0.0529 & 0.0591 \\
\hline $1-4$ & -3.8089 & -4.0109 & 0.0710 & 0.0721 \\
\hline $5-9$ & -5.0679 & -5.2037 & 0.0644 & 0.0731 \\
\hline $10-14$ & -5.3599 & -5.4923 & 0.0711 & 0.0781 \\
\hline $15-19$ & -4.9191 & -5.0586 & 0.0702 & 0.0819 \\
\hline $20-24$ & -4.6638 & -4.7623 & 0.0699 & 0.0793 \\
\hline $25-29$ & -4.6490 & -4.6972 & 0.0715 & 0.0750 \\
\hline $30-34$ & -4.6194 & -4.6055 & 0.0721 & 0.0687 \\
\hline $35-39$ & -4.5045 & -4.4505 & 0.0701 & 0.0627 \\
\hline $40-44$ & -4.3463 & -4.2658 & 0.0676 & 0.0587 \\
\hline $45-49$ & -4.1166 & -4.0037 & 0.0630 & 0.0521 \\
\hline $50-54$ & -3.8347 & -3.7177 & 0.0558 & 0.0466 \\
\hline $55-59$ & -3.5145 & -3.4045 & 0.0480 & 0.0420 \\
\hline $60-64$ & -3.1804 & -3.0659 & 0.0400 & 0.0366 \\
\hline $65-69$ & -2.8296 & -2.7170 & 0.0335 & 0.0319 \\
\hline $70-74$ & -2.4944 & -2.3777 & 0.0272 & 0.0286 \\
\hline $75-79$ & -2.1768 & -2.0521 & 0.0259 & 0.0267 \\
\hline $80+$ & -1.4311 & -1.3943 & 0.0258 & 0.0268 \\
\hline
\end{tabular}

Table 5: $\hat{k}_{t}$ for Indian population based on decade wise life tables (1901-11 to 2001-11)

\begin{tabular}{|l|l|l|l|l|l|l|}
\hline Decade & $\mathbf{1 9 0 1 - 1 1}$ & $\mathbf{1 9 1 1 - 2 1}$ & $\mathbf{1 9 2 1 - 3 1}$ & $\mathbf{1 9 3 1 - 4 1}$ & $\mathbf{1 9 4 1 - 5 1}$ & $\mathbf{1 9 5 1 - 6 1}$ \\
\hline$\hat{k}_{t}($ Female $)$ & 13.191 & 12.818 & 11.325 & 9.351 & 6.901 & 3.237 \\
\hline$\hat{k}_{t}$ (Male) & 12.800 & 12.639 & 11.175 & 9.078 & 6.140 & 2.120 \\
\hline Decade & $\mathbf{1 9 6 1 - 7 1}$ & $\mathbf{1 9 7 1 - 8 1}$ & $\mathbf{1 9 8 1 - 9 1}$ & $\mathbf{1 9 9 1 - 0 1}$ & $\mathbf{2 0 0 1 - 1 1}$ & \\
\hline$\hat{k}_{t}$ (Female) & -0.569 & -5.053 & -13.069 & -15.973 & -22.160 & \\
\hline$\hat{k}_{t}$ (Male) & -2.328 & -7.669 & -12.167 & -14.000 & -17.788 & \\
\hline
\end{tabular}

In Table 6, we have presented the actual LE and LE based on fitted LC model at birth and at ages 20-24, 40-44 and 60-64 for three selected decades. 


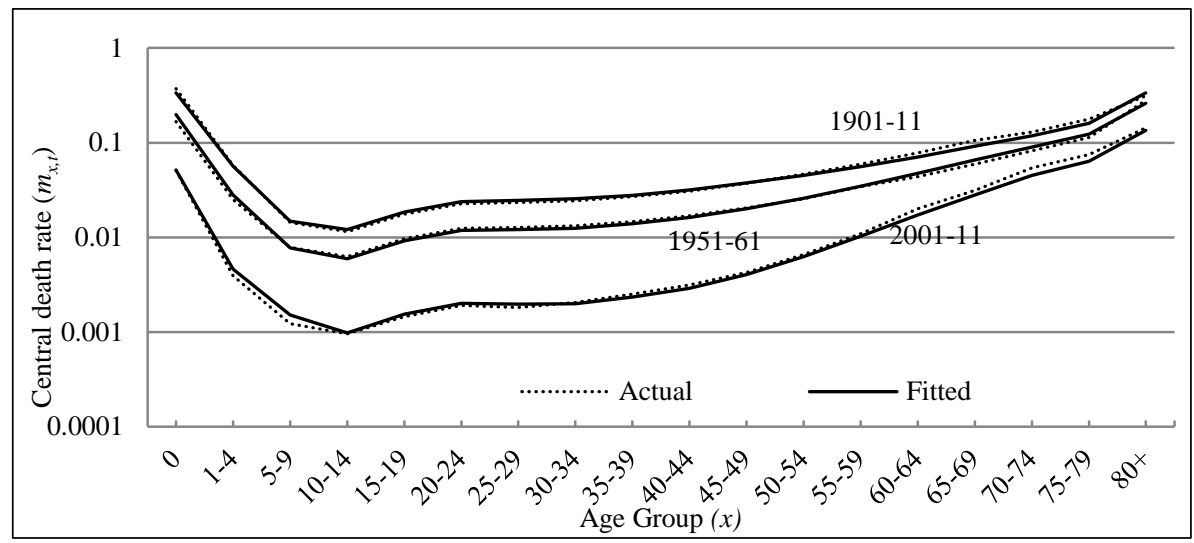

(a) Female Population

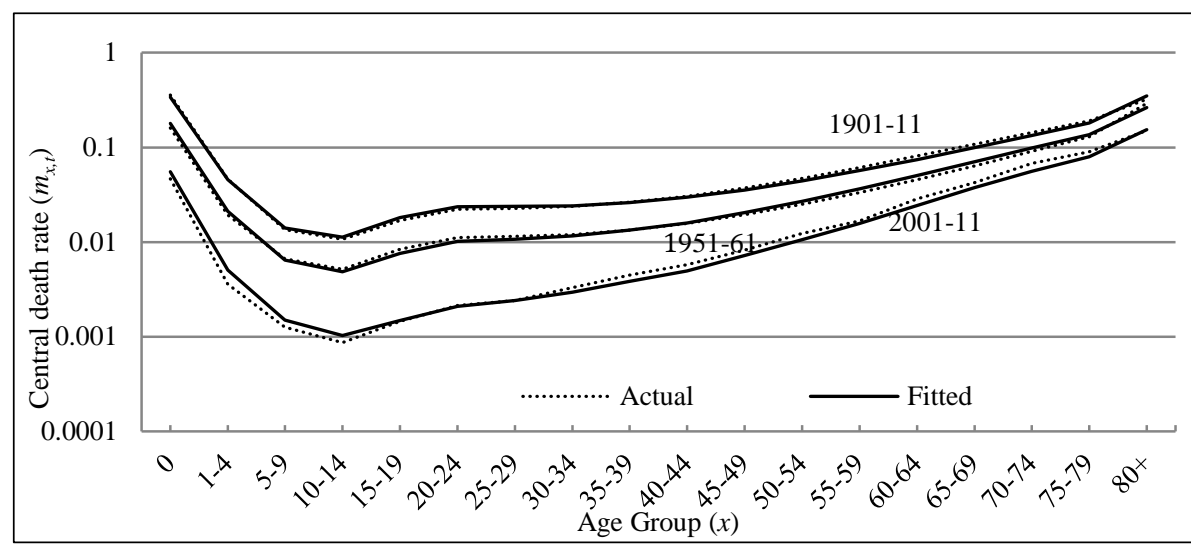

(b) Male Population

Figure 2: Actual and fitted age group specific central death rates for three decades

From the values of actual and model based LE, we observed a good fit. To obtain model based LE, we have used definitions for construction of abridged life table given by Greenwood (1922) and Chiang (1984). 
Table 6: Observed and fitted life expectancy at some selected age groups using the LC model

\begin{tabular}{|c|c|c|c|c|c|c|c|}
\hline $\begin{array}{c}\text { Life } \\
\text { Expectancy } \\
\text { at }\end{array}$ & \multirow{2}{*}{$\begin{array}{c}\text { Actual/ } \\
\text { Fitted }\end{array}$} & \multicolumn{3}{|c|}{ Female } & \multicolumn{3}{c|}{ Male } \\
\cline { 3 - 8 } Birth & Actual & 23.23 & 39.89 & 67.30 & 24.76 & 42.04 & 63.81 \\
\cline { 2 - 8 } & Fitted & 24.05 & 38.70 & 66.24 & 25.31 & 41.18 & 63.04 \\
\hline \multirow{2}{*}{$20-24$} & Actual & 27.10 & 36.24 & 52.92 & 27.21 & 36.96 & 48.73 \\
\cline { 2 - 8 } & Fitted & 26.89 & 36.35 & 52.11 & 27.25 & 36.68 & 48.97 \\
\hline \multirow{2}{*}{$40-44$} & Actual & 18.08 & 24.23 & 34.71 & 17.91 & 24.27 & 31.09 \\
\cline { 2 - 8 } & Fitted & 18.40 & 23.89 & 33.89 & 18.47 & 23.47 & 31.16 \\
\hline \multirow{2}{*}{$60-64$} & Actual & 9.29 & 12.77 & 17.67 & 8.98 & 12.27 & 15.72 \\
\cline { 2 - 8 } & Fitted & 9.90 & 12.00 & 16.56 & 9.41 & 11.55 & 15.22 \\
\hline
\end{tabular}

\section{Forecasting}

Forecasting is the main aim behind the stochastic modeling. One of the noteworthy property of the LC model is that, once it is fitted (i.e. once values of $\hat{a}_{x}, \hat{b}_{x}$ and $\hat{k}_{t}$ are found), only the mortality index $\left(k_{t}\right)$ over time needs to be forecasted for future time points. Lee and Carter (1992) fitted autoregressive integrated moving average (ARIMA) $(0,1,0)$ (i.e. random walk with drift) for modeling mortality index $k_{t}$ for US population and also suggested to use the appropriate ARIMA models for different populations. We have considered some possible choices of ARIMA models for modeling mortality index $k_{t}$. Table 7 includes values of Akaike Information Criteria (AIC) and Bayesian Information Criteria (BIC) for considered models. According to AIC and BIC, $\operatorname{ARIMA}(1,2,0)$ and $\operatorname{ARIMA}(0,2,0)$ are best fitted models for mortality index $k_{t}$ estimated by SVD for Indian female and male populations respectively. Values in Table 7 are obtained by the R 'forecast' package. (see Hyndman, and Khandakar, (2008)). We have used best fitted ARIMA models for forecasting future values of mortality index, $k_{t}$ and other corresponding quantities of life table.

In the Table 8, we have given the forecasted values of mortality index, $k_{t}$ along with its $95 \%$ confidence intervals (CI) for next five decades. These values are forecasted one by one for each next decade and then by adding the forecasted 
Table 7: Fitted ARIMA models for estimated mortality index $k_{t}$

\begin{tabular}{|c|c|c|c|c|}
\hline \multirow{2}{*}{ Model } & \multicolumn{2}{|c|}{ Female } & \multicolumn{2}{c|}{ Male } \\
\cline { 2 - 5 } & AIC & BIC & AIC & BIC \\
\hline ARIMA(2,1,2) with drift & 46.36 & 48.18 & 41.69 & 43.51 \\
\hline ARIMA(2,1,1) with drift & 46.37 & 47.88 & 39.71 & 41.22 \\
\hline ARIMA(1,1,2) with drift & 44.74 & 46.25 & 39.74 & 41.26 \\
\hline ARIMA(1,1,1) with drift & 45.78 & 46.99 & 37.82 & 39.03 \\
\hline ARIMA(1,1,0) with drift & 44.57 & 45.48 & 36.04 & 36.95 \\
\hline ARIMA(0,1,1) with drift & 44.97 & 45.87 & 36.04 & 36.94 \\
\hline ARIMA(0,1,0) with drift & 43.33 & 43.93 & 37.44 & 38.04 \\
\hline ARIMA(1,2,0) without drift & $\mathbf{4 1 . 0 1}$ & $\mathbf{4 1 . 4 1}$ & 35.03 & 35.42 \\
\hline ARIMA(0,2,0) without drift & 43.50 & 43.70 & $\mathbf{3 3 . 0 4}$ & $\mathbf{3 3 . 2 4}$ \\
\hline
\end{tabular}

Table 8: Forecasted values of mortality index $k_{t}$ with $95 \% \mathrm{CI}$

\begin{tabular}{|c|c|c|}
\hline Decade & Female & Male \\
\hline $2011-21$ & $-26.19(-29.78,-22.60)$ & $-21.58(-24.24,-18.91)$ \\
\hline $2021-31$ & $-31.65(-35.06,-28.24)$ & $-25.36(-27.89,-22.84)$ \\
\hline $2031-41$ & $-36.16(-39.40,-32.91)$ & $-29.15(-31.56,-26.74)$ \\
\hline $2041-51$ & $-41.30(-44.41,-38.20)$ & $-32.94(-35.24,-30.63)$ \\
\hline $2051-61$ & $-46.02(-49.00,-43.03)$ & $-36.73(-38.94,-34.51)$ \\
\hline
\end{tabular}

value in the previous values of $k_{t}$ and again by using best fitted model, next decade's value for $k_{t}$ was forecasted and so on. At each forecasting stage we got the same model with different parameters. We observed that in next five decades mortality are expected to decline for both female and male population in India. This is due to decreasing nature of $k_{t}$.

We have forecasted values of age specific death rate, $m_{x t}$ by using estimated parameters $\hat{a}_{x}, \hat{b}_{x}$ and forecasted values of mortality index $k_{t}$. Table 9 reveals the forecasted age specific central death rates in terms of deaths per 100,000 for the five decades, 2011-21, 2021-31, 2031-41, 2041-51 and 2051-61.

We observed that infant mortality rate will decline from 42 to 15 per thousand for female and 44 to 18 for male from period 2011-21 to 2051-61. By the decade 2051-61, deaths rates for age groups between 1 to 49 years for female and age groups 5 to 34 years for male expected to be lower than one per thousand. The age specific death rates will continue to be lower for female population as compare to the male population for all five decades. Table 10 presents the LE along with $95 \% \mathrm{CI}$ at birth and for the age groups 20-24, 40-44 and 60-64. 
Table 9: Forecasted values of age specific central death rates in terms of deaths per 100,000 for Indian population

\begin{tabular}{|c|c|c|c|c|c|c|c|c|c|c|}
\hline \multirow[b]{2}{*}{$\begin{array}{l}\text { Age } \\
\text { Group }\end{array}$} & \multicolumn{5}{|c|}{ Female } & \multicolumn{5}{|c|}{ Male } \\
\hline & $\begin{array}{c}\text { 2011- } \\
21\end{array}$ & $\begin{array}{c}\text { 2021- } \\
31\end{array}$ & $\begin{array}{c}2031- \\
41\end{array}$ & $\begin{array}{c}\text { 2041- } \\
51\end{array}$ & $\begin{array}{c}2051- \\
61\end{array}$ & $\begin{array}{c}2011- \\
21\end{array}$ & $\begin{array}{c}\text { 2021- } \\
31\end{array}$ & $\begin{array}{c}2031- \\
41\end{array}$ & $\begin{array}{c}2041- \\
51\end{array}$ & $\begin{array}{c}2051- \\
61\end{array}$ \\
\hline 0 & 4174 & 3126 & 2463 & 1875 & 1461 & 4429 & 3540 & 2830 & 2262 & 1808 \\
\hline $1-4$ & 345 & 234 & 170 & 118 & 84 & 383 & 291 & 222 & 169 & 128 \\
\hline $5-9$ & 117 & 82 & 61 & 44 & 33 & 114 & 86 & 65 & 49 & 38 \\
\hline 10-14 & 73 & 50 & 36 & 25 & 18 & 76 & 57 & 42 & 31 & 23 \\
\hline 15-19 & 116 & 79 & 58 & 40 & 29 & 109 & 80 & 58 & 43 & 31 \\
\hline $20-24$ & 151 & 103 & 75 & 53 & 38 & 154 & 114 & 85 & 63 & 46 \\
\hline $25-29$ & 147 & 100 & 72 & 50 & 36 & 181 & 136 & 102 & 77 & 58 \\
\hline 30-34 & 149 & 101 & 73 & 50 & 36 & 227 & 175 & 135 & 104 & 80 \\
\hline $35-39$ & 177 & 120 & 88 & 61 & 44 & 302 & 238 & 188 & 148 & 117 \\
\hline $40-44$ & 220 & 152 & 112 & 79 & 58 & 396 & 317 & 254 & 203 & 163 \\
\hline $45-49$ & 313 & 222 & 167 & 121 & 90 & 593 & 487 & 400 & 328 & 269 \\
\hline $50-54$ & 501 & 369 & 287 & 215 & 166 & 889 & 745 & 625 & 524 & 439 \\
\hline $55-59$ & 847 & 651 & 525 & 410 & 327 & 1341 & 1144 & 976 & 832 & 709 \\
\hline $60-64$ & 1457 & 1171 & 978 & 796 & 659 & 2115 & 1841 & 1602 & 1395 & 1214 \\
\hline $65-69$ & 2452 & 2042 & 1756 & 1477 & 1261 & 3316 & 2938 & 2604 & 2307 & 2044 \\
\hline $70-74$ & 4049 & 3490 & 3088 & 2684 & 2361 & 5000 & 4486 & 4025 & 3611 & 3240 \\
\hline $75-79$ & 5759 & 5001 & 4451 & 3896 & 3449 & 7215 & 6520 & 5892 & 5324 & 4811 \\
\hline $80+$ & 1216 & 10571 & 9411 & 8242 & 7299 & 13918 & 12576 & 11363 & 10267 & 9277 \\
\hline
\end{tabular}

LE at birth will increase from 71.1 (CI: 68.3, 73.7) to 83.6 (CI: 81.9, 85.4) for female population and from 67.2 (CI: 65.0, 69.3) to 77.5(CI: 76.2, 78.8) for male population from the decade 2011-21 to 2051-61.

By the decade 2051-61, life expectancy at age group 60-64 will reach to 26.9 years for female and 22.6 years for male population.

\section{Actuarial Application}

For evaluation of actuarial quantities we have used the forecasted values of central death rates in terms of number of deaths per 100,000 as reported in Table 9. We have derived and presented values of Net Single Premium (NSP) of whole life insurance, NSP for 20-year term life insurance, Actuarial Present Value (APV) of whole life annuities and 20-year temporary annuities at some selected ages. In order to find these NSP of life insurance and APV of life annuities, we need to find life table in the complete form (that is life table for all integer ages instead of groups). For the estimation of complete sets of age specific central mortality rates for each age year we have used interpolative method for initial estimates and Whittaker graduation for smoothing. This method is thoroughly discussed by Li and Chan (2004). 
Table 10: Forecasted values of life expectancy at different age groups with $95 \%$ confidence intervals

\begin{tabular}{|c|c|c|c|c|c|}
\hline \multirow{2}{*}{ Gender } & \multirow{2}{*}{ Decade } & \multicolumn{4}{|c|}{ Life expectancy with $95 \%$ CI at } \\
\hline & & Birth & 20-24 & $40-44$ & 60-64 \\
\hline \multirow{5}{*}{ Female } & 2011-21 & $\begin{array}{c}71.1 \\
(68.3,73.7)\end{array}$ & $\begin{array}{c}56.1 \\
(54.3,57.8)\end{array}$ & $\begin{array}{c}37.5 \\
(36.1,390)\end{array}$ & $\begin{array}{c}20.0 \\
(18.9,21.1)\end{array}$ \\
\hline & 2021-31 & $\begin{array}{c}75.0 \\
(72.6,77.2)\end{array}$ & $\begin{array}{c}58.7 \\
(57.1,60.3)\end{array}$ & $\begin{array}{c}39.8 \\
(38.4,41.1)\end{array}$ & $\begin{array}{c}21.7 \\
(20.6,22.8)\end{array}$ \\
\hline & $2031-41$ & $\begin{array}{c}77.8 \\
(75.8,79.8)\end{array}$ & $\begin{array}{c}60.8 \\
(59.3,62.3)\end{array}$ & $\begin{array}{c}41.6 \\
(40.3,43.0)\end{array}$ & $\begin{array}{c}23.2 \\
(22.1,24.4)\end{array}$ \\
\hline & $2041-51$ & $\begin{array}{c}80.9 \\
(79.1,82.7)\end{array}$ & $\begin{array}{c}63.2 \\
(61.8,64.7)\end{array}$ & $\begin{array}{c}43.8 \\
(42.5,45.1)\end{array}$ & $\begin{array}{c}25.1 \\
(23.9,26.3)\end{array}$ \\
\hline & & $\begin{array}{c}83.6 \\
(81.9,85.4)\end{array}$ & $\begin{array}{c}65.4 \\
(64.0,66.9)\end{array}$ & $\begin{array}{c}45.9 \\
(44.5,47.2)\end{array}$ & $\begin{array}{c}26.9 \\
(25.7,28.2)\end{array}$ \\
\hline \multirow{5}{*}{ Male } & 2011-21 & $\begin{array}{c}67.2 \\
(65.0,69.3)\end{array}$ & $\begin{array}{c}52.2 \\
(50.7,53.5)\end{array}$ & $\begin{array}{c}34.0 \\
(32.8,35.1)\end{array}$ & $\begin{array}{c}17.8 \\
(17.0,18.5)\end{array}$ \\
\hline & 2021-31 & $\begin{array}{c}70.1 \\
(68.2,71.9)\end{array}$ & $\begin{array}{c}54.1 \\
(52.8,55.3)\end{array}$ & $\begin{array}{c}35.5 \\
(34.5,36.6)\end{array}$ & $\begin{array}{c}18.9 \\
(18.1,19.6)\end{array}$ \\
\hline & $2031-41$ & $\begin{array}{c}72.7 \\
(71.1,74.3)\end{array}$ & $\begin{array}{c}56.0 \\
(54.8,57.1)\end{array}$ & $\begin{array}{c}37.1 \\
(36.1,38.1)\end{array}$ & $\begin{array}{c}20.0 \\
(19.3,20.8)\end{array}$ \\
\hline & $2041-51$ & $\begin{array}{c}75.2 \\
(73.7,76.6)\end{array}$ & $\begin{array}{c}57.8 \\
(56.7,58.9)\end{array}$ & $\begin{array}{c}38.7 \\
(37.7,39.7)\end{array}$ & $\begin{array}{c}21.3 \\
(20.5,22.1)\end{array}$ \\
\hline & $2051-61$ & $\begin{array}{c}77.5 \\
(76.2,78.8)\end{array}$ & $\begin{array}{c}59.6 \\
(58.5,60.7)\end{array}$ & $\begin{array}{c}40.3 \\
(39.4,41.3)\end{array}$ & $\begin{array}{c}22.6 \\
(21.8,23.4)\end{array}$ \\
\hline
\end{tabular}

\subsection{Some Actuarial Terms and Notations:}

Suppose random variable $X$ denotes the new born's age at the time of death. That is life length of an individual, $X$ is a non negative continuous random variable with distribution function $F$. In the theory of life insurance, the main random variable of interest is the time until death random variable for person aged $x$ and it is denoted by $T(x)$. It is to be noted that distribution function of $T(x)$ is the same as conditional distribution function of $X-x$ given that $X>x$. The distribution function of $T(x)$ is given by,

$$
F_{T(x)}(t)=P[(x) \leq t]=P[X-x \leq t \mid X>x]={ }_{t} q_{x}
$$

where ${ }_{t} q_{x}$ denote the probability that person aged $x$ dies in the age interval $(x, x+t]$.

A discrete random variable $K(x)$ associated with future life $T(x)$ is defined as the largest integer strictly smaller than $T(x) . K(x)$ is an integer valued random 
variable. It is known as curtate future lifetime at age $x$. The probability mass function ( $\mathrm{pmf}$ ) of $K(x)$ is obtained from distribution of $T(x)$. For $x=0,1,2, \ldots$, pmf of $K(x)$ is

$$
P[K(x)=k]=P[k<T(x) \leq k+1]={ }_{k} p_{x} \times q_{x+k},
$$

where ${ }_{k} p_{x}=1-{ }_{k} q_{x}$.

Let $i$ be the effective rate of interest, which is interest earned on 1 unit invested in one period (generally one period is one year) and $v$ is the present value or discounted value of unit 1 payable after one period. Hence, $v=1 /(1+i)$. The NSP for whole life insurance payable for one unit benefit payable at the end of year of death of person aged $x$ years, denoted by $A_{x}$ and its expression is given by,

$$
A_{x}=\sum_{k=0}^{\infty} v^{k+1} \times{ }_{k} p_{x} \times q_{x+k}
$$

The NSP for $n$-year term life insurance payable for one unit benefit payable at the end of year of death of person aged $x$ years if death occur within $n$ year from the policy issue, denoted by $A_{x: \bar{n} \mid}^{1}$ and its expression is given by,

$$
A_{x: \bar{n} \mid}^{1}=\sum_{k=0}^{n-1} v^{k+1} \times{ }_{k} p_{x} \times q_{x+k}
$$

The APV of whole life annuity due for one unit payment at the beginning of each year throughout the remaining lifetime of an individual now aged $x$ denoted by $\ddot{a}_{x}$ and its expression is given by,

$$
\ddot{a}_{x}=\sum_{k=0}^{\infty} v^{k} \times{ }_{k} p_{x}
$$

The APV of $n$-year temporary life annuity due for one unit payment at the beginning of each year for the next $n$ years or till survivor whichever occur first for an individual now aged $x$ denoted by $\ddot{a}_{x: \bar{n} \mid}$ and its expression is given by,

$$
\ddot{a}_{x: \bar{n} \mid}=\sum_{k=0}^{n-1} v^{k} \times{ }_{k} p_{x}
$$

Table 11 presents the values of $A_{x}$ and $A_{x: \overline{20} \mid}^{1}$ calculated at $6.75 \%$ effective rate of interest per annum. (as per current repo rate on 29.02.2016 of Reserve Bank of India). In the Table 12, we have reported the APV of life annuities, $\ddot{a}_{x}$ and $\ddot{a}_{x: \overline{20} \mid}$ calculated at $6.75 \%$ effective rate of interest per annum (as per repo rate on 29.02.2016 of Reserve Bank of India). These values of NSP of life 
insurances or APV of life annuities may be useful for finding total cost of one time premium for person of age $x=0,10,20,40$ and 60 .

Table 11: Forecasted values of NSP of whole life insurance, $A_{x}$ and for 20-year term life insurance, $A_{x: \overline{20} \mid}^{1}$ at some selected ages

\begin{tabular}{|c|c|c|c|c|c|c|c|}
\hline \multirow{2}{*}{ NSP } & \multirow{2}{*}{ Gender } & \multirow{2}{*}{ Decade } & \multicolumn{5}{|c|}{ Age $(x)$} \\
\hline & & & $\mathbf{0}$ & 10 & 20 & 40 & 60 \\
\hline \multirow{10}{*}{$A_{x}$} & \multirow{5}{*}{ Female } & 2011-21 & 0.0673 & 0.0315 & 0.0480 & 0.1209 & 0.3226 \\
\hline & & 2021-31 & 0.0506 & 0.0249 & 0.0392 & 0.1060 & 0.2982 \\
\hline & & $2031-41$ & 0.0402 & 0.0208 & 0.0336 & 0.0956 & 0.2795 \\
\hline & & $2041-51$ & 0.0310 & 0.0172 & 0.0285 & 0.0854 & 0.2595 \\
\hline & & $2051-61$ & 0.0246 & 0.0146 & 0.0249 & 0.0775 & 0.2425 \\
\hline & \multirow{5}{*}{ Male } & 2011-21 & 0.0737 & 0.0381 & 0.0608 & 0.1541 & 0.3648 \\
\hline & & $2021-31$ & 0.0597 & 0.0323 & 0.0528 & 0.1405 & 0.3457 \\
\hline & & $2031-41$ & 0.0485 & 0.0276 & 0.0461 & 0.1285 & 0.3274 \\
\hline & & $2041-51$ & 0.0395 & 0.0238 & 0.0406 & 0.1176 & 0.3099 \\
\hline & & $2051-61$ & 0.0323 & 0.0207 & 0.0359 & 0.1079 & 0.2932 \\
\hline \multirow{10}{*}{$A_{x: \overline{20} \mid}^{1}$} & \multirow{5}{*}{ Female } & $2011-21$ & 0.0572 & 0.0155 & 0.0216 & 0.0551 & 0.2546 \\
\hline & & 2021-31 & 0.0423 & 0.0111 & 0.0159 & 0.0436 & 0.2257 \\
\hline & & 2031-41 & 0.0329 & 0.0086 & 0.0124 & 0.0363 & 0.2040 \\
\hline & & $2041-51$ & 0.0248 & 0.0064 & 0.0095 & 0.0296 & 0.1815 \\
\hline & & 2051-61 & 0.0191 & 0.0050 & 0.0076 & 0.0248 & 0.1629 \\
\hline & \multirow{5}{*}{ Male } & 2011-21 & 0.0610 & 0.0170 & 0.0277 & 0.0845 & 0.3066 \\
\hline & & 2021-31 & 0.0485 & 0.0133 & 0.0223 & 0.0729 & 0.2835 \\
\hline & & $2031-41$ & 0.0386 & 0.0105 & 0.0180 & 0.0629 & 0.2616 \\
\hline & & $2041-51$ & 0.0307 & 0.0084 & 0.0147 & 0.0545 & 0.2409 \\
\hline & & 2051-61 & 0.0244 & 0.0068 & 0.0120 & 0.0472 & 0.2216 \\
\hline
\end{tabular}

\section{Conclusions}

We modeled the central mortality rates of Indian population by using the LC model estimated by SVD, approach based on decade-wise mortality data from 1901-11 to 2001-11. We observed the following.

i) The general pattern of mortality $\left(\hat{a}_{x}\right)$ for both female and male populations shown high infant mortality, an accidental hump around ages 20 years and nearly exponential increase at older ages.

ii) The sensitivity of mortality $\left(\hat{b}_{x}\right)$ has shown mortality decline at high rate for ages 25-34 years for female and for ages 15-24 years for male population than other ages.

iii) Mortality index $\left(\hat{k}_{t}\right)$ has shown decreasing trend.

iv) Improvement in female mortality is larger than male mortality.

v) Mortality improvement and its impact on actuarial quantities are observed at all ages for Indian female and male populations. 
Table 12: Forecasted values of APV of whole life annuity, $\ddot{a}_{x}$ and for 20-year temporary annuity, $\ddot{a}_{x: \overline{20} \mid}$ at some selected ages

\begin{tabular}{|c|c|c|c|c|c|c|c|}
\hline \multirow{2}{*}{ APV } & \multirow{2}{*}{ Gender } & \multirow{2}{*}{ Decade } & \multicolumn{5}{|c|}{ Age $(x)$} \\
\hline & & & $\mathbf{0}$ & 10 & 20 & 40 & 60 \\
\hline \multirow{10}{*}{$\ddot{a}_{x}$} & \multirow{5}{*}{ Female } & 2011-21 & 14.7508 & 15.3161 & 15.0560 & 13.9030 & 10.7123 \\
\hline & & $2021-31$ & 15.0143 & 15.4209 & 15.1952 & 14.1392 & 11.0985 \\
\hline & & 2031-41 & 15.1797 & 15.4861 & 15.2840 & 14.3034 & 11.3953 \\
\hline & & $2041-51$ & 15.3247 & 15.5433 & 15.3638 & 14.4635 & 11.7110 \\
\hline & & 2051-61 & 15.4260 & 15.5836 & 15.4215 & 14.5889 & 11.9795 \\
\hline & \multirow{5}{*}{ Male } & $2011-21$ & 14.6491 & 15.2127 & 14.8526 & 13.3785 & 10.0451 \\
\hline & & 2021-31 & 14.8703 & 15.3047 & 14.9798 & 13.5921 & 10.3471 \\
\hline & & $2031-41$ & 15.0478 & 15.3788 & 15.0853 & 13.7832 & 10.6366 \\
\hline & & $2041-51$ & 15.1900 & 15.4389 & 15.1730 & 13.9543 & 10.9133 \\
\hline & & $2051-61$ & 15.3040 & 15.4879 & 15.2464 & 14.1076 & 11.1773 \\
\hline \multirow{10}{*}{$\ddot{a}_{x: \overline{20}}$} & \multirow{5}{*}{ Female } & $2011-21$ & 11.5994 & 12.1030 & 12.0278 & 11.7191 & 10.0201 \\
\hline & & 2021-31 & 11.7703 & 12.1439 & 12.0846 & 11.8199 & 10.2866 \\
\hline & & 2031-41 & 11.8773 & 12.1684 & 12.1189 & 11.8848 & 10.4823 \\
\hline & & 2041-51 & 11.9708 & 12.1891 & 12.1482 & 11.9437 & 10.6813 \\
\hline & & $2051-61$ & 12.0359 & 12.2031 & 12.1681 & 11.9865 & 10.8429 \\
\hline & \multirow{5}{*}{ Male } & $2011-21$ & 11.5520 & 12.0849 & 11.9740 & 11.4646 & 9.5127 \\
\hline & & 2021-31 & 11.6949 & 12.1194 & 12.0258 & 11.5673 & 9.7352 \\
\hline & & $2031-41$ & 11.8089 & 12.1461 & 12.0665 & 11.6548 & 9.9415 \\
\hline & & $2041-51$ & 11.8998 & 12.1667 & 12.0986 & 11.7294 & 10.1323 \\
\hline & & 2051-61 & 11.9721 & 12.1828 & 12.1241 & 11.7930 & 10.3083 \\
\hline
\end{tabular}

\section{Acknowledgement}

Authors are very much indebted to anonymous referee for valuable suggestions and constructive comments on earlier version of paper which improve the quality and presentation of paper. First author would like to thanks to Department of Science and Technology (INSPIRE Division), New Delhi, India for financial assistance through INSPIRE fellowship for this research.

\section{References}

1. Aberathna, W., Alles, L., Wickremasinghe, W. N., and Hewapathirana, I. (2014). Modeling and Forecasting Mortality in Sri Lanka. Sri Lankan Journal of Applied Statistics, 15(3). DOI:10.4038/sljastats.v15i3.7794 
Modeling and Forecasting Mortality Using the Lee-Carter Model for Indian Population

2. Chiang, C. L. (1984). The life Table and its applications. Malabar: Robert E Krieger Publishing Company.

3. Greenwood, M. (1922). Discussion on the Value of Life-Tables in Statistical Research. Journal of the Royal Statistical Society, 85(4), 537. DOI:10.2307/2341122

4. Hyndman, R. J., and Khandakar, Y. (2008). Automatic Time Series Forecasting: The forecast Package for R. Journal of Statistical Software, 27(3). DOI:10.18637/jss.v027.i03

5. Koissi, M.-C., Shapiro, A. F., and Högnäs, G. (2006). Evaluating and extending the Lee-Carter model for mortality forecasting: Bootstrap confidence interval. Insurance: Mathematics and Economics, 38(1), 1-20. DOI:10.1016/j.insmatheco.2005.06.008

6. Lee, R. D., and Carter, L. R. (1992). Modeling and Forecasting U.S. Mortality. Journal of the American Statistical Association, 87(419), 659671. DOI:10.1080/01621459.1992.10475265

7. Lee, R.D., and Rofman, R. (1994). Modeling and forecasting mortality in Chile. Notas, 22 (59), 182-213.

8. Li, N., Lee, R., and Tuljapurkar, S. (2004). Using the Lee-Carter Method to Forecast Mortality for Populations with Limited Data. International Statistical Review, 72(1), 19-36. DOI:10.1111/j.1751-5823.2004.tb00221.x

9. Li, S. H. and Chan, W. S. (2004). Estimation of complete period life Tables for Singaporeans. Journal of Actuarial Practice, 11, 129-146.

10. Lin, J. (1995). Changing Kinship Structure and its Implications for OldAge Support in Urban and Rural China. Population Studies, 49(1), 127145. DOI:10.1080/0032472031000148286 
11. Singh, A. and Ram, F. (2004). Forecasting mortality in India. Rawat Publications, Jaipur, Population Health and Development. Ed. TK Roy, M Guruswamy and P Arokiasamy.

12. Tuljapurkar, S., Nan, L. and Boe, C., (2000). A universal pattern of mortality decline in the G7 countries. Nature, 405, 789-792.

13. Wilmoth, J.R., (1996). Mortality Projections for Japan: A Comparison of Four Methods. Health and Mortality among Elderly Population. In: Caselli, G., Lopez, A. (Eds.), Oxford University Press, New York.

14. Yadav, A., Yadav, S., and Kesarwani, R. (2012). Decelerating Mortality Rates in Older Ages and its Prospects through Lee-Carter Approach. PLoS ONE, 7(12): e50941. DOI:10.1371/journal.pone.0050941

15. Yasungnoen, N., and Sattayatham, P. (2016). Forecasting Thai Mortality by Using the Lee-Carter Model. Asia-Pacific Journal of Risk and Insurance, 10(1), 91-105. DOI:10.1515/apjri-2014-0042 